\title{
Trigeminal neuralgia after corneal transplantation - a case report
}

Neuralgia do trigêmeo pós-transplante de córnea - relato de caso

Daniel Oliveira Araújo' ${ }^{(1)}$, Luis Felipe Pohlmann Tabarelli² (D), Luiz Felipe Lynch ${ }^{3}$ (D)

1 Medical School, Faculdade Pernambucana de Saúde, Recife, PE, Brazil.

Corneal transplantation; Trigeminal neuralgia; Eye pain; Pain management; Malpractice

Descritores:

Transplante de córnea; Neuralgia do trigêmeo; Dor ocular; Manejo da dor; Imperícia

Received on: Feb 5, 2021

Accepted on: May 6,2021

Corresponding author: Luiz Felipe Lynch de Moraes E-mail: luizfelipelynch@hotmail.com R. Antônio Gomes de Freitas, 131 - Ilha do Leite, Recife - PE, 50070-480 Institution:

Serviço Oftalmológico de Pernambuco SEOPE, Recife, PE, Brazil.

Conflicts of interest: none.

Financial support: the authors received no financial support for this work.

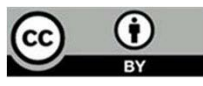

Copyright (C2021

\section{ABSTRACT}

Description of a patient with Fuchs endothelial dystrophy submitted to a corneal transplant, performed by Descemet membrane endothelial keratoplasty, which evolved with sudden, paroxysmal pain in the frontotemporal region, postoperatively. Due to the ophthalmologic picture of the patient, the attending physician believed in possible rejection of the graft, neglecting the complaint of pain. Even after a successful second transplant, performed due to primary failure, disabling pain persisted and the physician did not manage it. After years of investigation, consulting with several specialists, it was concluded the patient presented trigeminal neuralgia that had not been treated since the surgical procedure. In addition, it led to several psychosocial consequences. Therefore, it is essential to be aware trigeminal neuralgia is a possible outcome of corneal transplantation, and its symptoms should not be neglected by the attending physician, thus contributing to better management for transplanted patients.

\section{RESUMO}

Descrição do relato de caso de uma paciente com distrofia endotelial de Fuchs submetida a transplante de córnea, realizado pela técnica DMEK, que evoluiu com quadro de dor súbita, paroxística, em região frontotemporal, no pós-operatório. Devido ao quadro oftalmológico da paciente, o médico assistente acreditava em possível rejeição do enxerto, negligenciando a dor. Mesmo após sucesso do segundo transplante, realizado devido à falência primária, as dores incapacitantes persistiam, e nenhuma conduta, por parte do médico, foi realizada. Após anos de investigação, mediante consultas com diversos especialistas, concluiu-se que a paciente apresentava um quadro de neuralgia do nervo trigêmeo que não tinha sido tratada desde a realização do procedimento cirúrgico. Além disso, apresentava uma série de consequências psicossociais. Portanto, torna-se imprescindível entender que a neuralgia do nervo trigêmeo é um possível desfecho do transplante de córnea, e seus sintomas não devem ser negligenciados por parte do médico assistente, contribuindo para melhores condutas para os pacientes transplantados. 


\section{INTRODUCTION}

Corneal transplants are the most successful organ transplants in the human body and can be used to treat a wide range of corneal diseases. In recent decades, many techniques have been developed to improve the results of this procedure. Approximately 185 thousand corneal transplants are performed each year, making it the most common transplant worldwide. ${ }^{(1)}$ One indication for corneal transplant is treatment of Fuchs endothelial dystrophy, a disease characterized by slow and progressive decrease in number of endothelial cells, with consequent bilateral edema of the cornea and decreased visual acuity.

Severe complications of corneal transplants are transplant rejection, infection, glaucoma, graft failure, elevated refractive error, and disease recurrence. Eye pain is an uncommon condition of patients undergoing transplants and can be caused by eye surface irritation, elevation of intraocular pressure (IOP) and inflammation. Typically, eye pain after a transplant may be a sign of primary failure. Trigeminal neuralgia (TGN) is a rare cause of postoperative pain and has been little documented in the international literature..$^{(2)}$

Trigeminal neuralgia is a neuropathic pain that affects the cranial nerve $\mathrm{V}$ and is characterized by severe paroxysmal facial pain, of sudden onset, especially in areas where nerve branches are distributed. ${ }^{(3)}$ The pathophysiology of TGN has not been fully understood yet, and its causes are diverse. Nerve compression plays an important role in the development of this neuralgia, but it is not the only mechanism involved.

The diagnosis of TGN is based on clinical criteria and there are no specific tests. The third edition of the International Classification of Headache Disorders does not specify the diagnostic criteria for TGN after ophthalmic surgery. ${ }^{(4)}$ The lack of uniform clinical criteria hinders diagnostic accuracy, delaying treatment, and pain relief.

The objective of this work is to describe a case of TGN after ophthalmic surgery, its progression, and consequences, in addition to raising the discussion on the importance of early recognition of symptoms and diagnosis.

\section{CASE REPORT}

A 57-year-old female patient diagnosed as Fuchs endothelial dystrophy, in 2012. Due to disease progression and low visual acuity, the patient underwent a corneal transplant in the right eye by Descemet membrane endothelial keratoplasty (DMEK), associated with phacoemulsification with intraocular lens implantation (IOL). The surgery was performed under sedation and peribulbar anesthetic block, in December 2016. The procedure went uneventfully.

In the immediate postoperative period, still at the hospital, the patient presented severe periorbital pain, which was associated with the surgical procedure. On the first postoperative day, the clinical picture was as expected, according to the surgeon's records. On the $15^{\text {th }}$ postoperative day, the patient persisted with pain, also referring to burning sensation in the right eye. Ophthalmologic examination revealed mild hyperemia and edema 1+ and the therapeutic lens was removed. After 22 days, she was anxious and still complaining of pain. Ocular examination revealed hyperemia, corneal edema, and eyelid edema on the surgery side. On the $29^{\text {th }}$ day of surgery, the transplant was in place, but there was edema and the presence of epithelial detachment and pain. It was acknowledged as failure and a new transplant was suggested by the attending physician.

Periorbital pain was aching and disabling, the patient began a picture of distress that evolved to mild depression. She was waiting for the new surgery, hoping to relieve pain.

In the period between the first and second transplants, the patient went to the ophthalmologic emergency room on eight occasions, in the same place where she had been operated on, and was seen by seven different ophthalmologists, who oriented her to carry on follow-up with the attending physician, and not addressing the painful condition. The attending physician, in all postoperative consultations, stated she had nothing related to surgery.

In June 2017, approximately 6 months after the first transplant, a new endothelial transplant was performed. The procedure went uneventfully, and visual acuity improved. However, despite better ophthalmologic picture, periorbital pain persisted and was associated with anhidrosis in the frontotemporal region. During follow-up, the attending physician always minimized the symptoms, stating the eye was fine, with satisfactory vision and controlled pressure, and that the patient was anxious for no reason, since everything was satisfactory from the ophthalmological point of view.

Considering the aching, disabling pain, and no guidance at all on the part of the attending physician, the patient became more depressed, stopped working and stayed at home.

In June 2019, more than two years after onset of symptoms and several consultations with the attending physician (none of the authors) for follow-up of the transplant, the patient sought an ophthalmologist (none of 
the authors), at her family's insistence. She was referred to a neurologist, who diagnosed trigeminal neuralgia. Treatment with $75 \mathrm{mg}$ of pregabalin was initiated and the patient immediately improved pain and consequently depression, and resumed her activities of daily living.

\section{DISCUSSION Neuralgia after ophthalmic surgery}

Trigeminal neuralgia associated with ophthalmic procedures is a rare event, although recognized and described in the literature. This complication may be associated with peribulbar block or the ocular procedure itself. Lucena et al. described three cases of patients who developed TGN after ophthalmic surgery, demonstrating the condition may occur in individuals of different ages and undergoing diverse procedures. They showed pathophysiology and etiology of this syndrome, in such cases, have not been well understood yet. ${ }^{(3)}$ Jacobs-El et al. described the occurrence of this pathology associated with ophthalmic surgery in a 72-year-old man undergoing cataract surgery, under topical anesthesia. ${ }^{(2)}$ According to the authors, the patient's history of multiple sclerosis may have contributed to the development of TGN, since the demyelination process can lead to abnormal excitation of nociceptive neurons, causing disproportionate pain to stimulus. Thus, despite a rare episode, other studies have already observed the occurrence of this condition in patients undergoing ophthalmic surgery. In these studies, however, it was not possible to conclude whether some factors, such as vascular compression, previous demyelinating diseases, other comorbidities, or aspects related to anesthetic block and the procedure itself, were responsible for the development of this condition.

\section{Pain management}

Pain management is a common challenge in clinical practice, requiring special efforts from health professionals. Understanding pain as a symptom, disease or phenomenon is not always a simple process, but it is essential for the development of effective approaches to management. ${ }^{(5)}$ The situation is even more complex when it comes to chronic pain of unknown cause. In these scenarios, it is up to the physicians to relieve human suffering, even if they are unable to heal.

There is a consensus that alleviating human suffering is a medical obligation. However, according to the literature, this duty has been largely neglected. All types of pain remain largely untreated or undertreated. Some barriers to management of patients suffering from chronic pain have been identified in the literature. ${ }^{(6)}$ Among these, two stand out and fit what was observed in this case: the failure of physicians to identify pain as a priority in patient care, which relates to the prevalence of a curative model over a person-centered care paradigm, as well as the dominance of scientific approach over humanistic approach; the inability of physicians to develop appropriate relationships with their patients, which threatens the possibility of understanding the subjective language of pain.

\section{Miscellaneous causes and symptoms: neglect}

First, we believe the fact TGN is not a common outcome in postoperative corneal transplantation should be highlighted and, therefore, the delay in diagnosis of this complication is justified. However, even in the face of diagnostic difficulties, it is up to the physician to give due attention to the patients' complaints, seeking to relieve their burden. In this case, a more detailed history and physical examination could raise other presumptive diagnoses that could explain the pain of patients. Questions about the pattern of involvement, triggering factors, duration, territory, and paroxysm, could have helped initiating a direct treatment in advance, or at least have raised suspicion about neuropathic pain after the successful second transplant.

The presence of unexplained pain after success of the second transplant should have alerted the attending physician, drawing his attention to other causes of pain reported by the patient. Although TGN is an unusual but not impossible result, given the pain scenario, the physician could have paid attention to the patient, avoiding her suffering until diagnosis was made by another professional. However, according to the medical records, the patient was always satisfied, or at most, anxious. Clearly, the attending physician did not take the patient's complaints seriously, documenting erroneous information in the medical record; therefore, he was not able to guide the patient properly.

Trigeminal neuralgia can have various causes, such as vascular compression, anesthetic complication, or nerve damage during the procedure. According to the literature, it is often impossible to determine the etiology of symptoms. Thus, once symptoms of neuropathic pain have been identified in the trigeminal innervation region, the attending physician should focus on the patient's pain relief and treatment. Only if the patient's medical history reveals an evident, unmistakable, and reversible cause 
for TGN, the physician should investigate the etiology of pain, seeking to treat its cause.

We can conclude that TGN, despite an unusual outcome, when it occurs, is routinely neglected by attending physicians. Whether by medical negligence, lack of knowledge about this possibility, or considering the rare occurrence, the fact is that in the face of severe pain in the territory of the trigeminal nerve, not explainable by other etiologies, neuralgia should be considered. For this, it is necessary physicians listen carefully to complaints of their patients and value them, always seeking to understand the patterns related to pain. A detailed history-taking and well performed physical examination are essential to diagnose this condition. These two tools cannot be restricted to theoretical medical education, but should be applied in practice, as required.
Physicians must be sensitive and empathic towards their patients, especially when it comes to chronic and incurable pain.

\section{REFERENCES}

1. Gain P, Jullienne R, He Z, Aldossary M, Acquart S, Cognasse F, et al. Global Survey of Corneal Transplantation and Eye Banking. JAMA Ophthalmol. 2016;134(2):167-73.

2. Jacobs-El NB, Shaikh S. Retinal surgery-induced trigeminal neuralgia. Retin Cases Brief Rep. 2013;7(1):67-8.

3. Lucena MDP, Furno Sola F, Torres Soriano ME, Gerster FA. Trigeminal neuralgia associated with ophthalmic surgery: a case series. J Med Case Rep. 2018;12(1):256.

4. Nurmikko TJ, Eldridge PR. Trigeminal neuralgia--pathophysiology, diagnosis and current treatment. Br J Anaesth. 2001;87(1):117-32

5. Jukić M, Puljak L. Legal and Ethical Aspects of Pain Management. Acta Med Acad. 2018;47(1):18-26.

6. Carvalho AS, Martins Pereira S, Jácomo A, Magalhães S, Araújo J, Hernández-Marrero $P$, et al. Ethical decision making in pain management: a conceptual framework. J Pain Res. 2018;11:967-76. 